\title{
A Real Time Analysis of Service based using Mobile Phone Controlled Vehicle using DTMF for Accident Prevention
}

\author{
C.K. Gomathy, PhD \\ Assistant Professor \\ Department of CSE \\ SCSVMV University-Tamil Nadu.
}

\author{
V. Geetha \\ Assistant Professor \\ Department of CSE \\ SCSVMV University-Tamil Nadu.
}

\begin{abstract}
This paper explores direct phone-to-phone communication between the driver's phone \& the owner's phone to support mobile sensing applications. Direct communication between driver's phone \& owner's phone is an important in improving data collection efficiency and sharing participatory sensing information in an inexpensive manner. We design a practical and optimized communication mechanism for direct phone-tophone data transfer to the driver's phone that strategically enables phone-to-phone communication. This paper makes use of the DTMF technology available on mobile phones to control the vehicle activities. We employ various sensors in the vehicle which sends us the information about the vehicle activities. In case of occurrence of any abnormalities in the functioning of vehicle, the sensors immediately detect these abnormalities \& a message is sent to the vehicle owner. By the use of the DTMF technology in the mobile phone, the owner can control these abnormalities from a remote place.
\end{abstract}

\section{Keywords}

Service Oriented System, Performance identification, DTMF, Accident identification, Speed Control, Vechicle Management System.

\section{INTRODUCTION}

The main aim of this system is to monitor and control the vehicle activities from a remote place. This system makes use of the DTMF technology available on the mobile phones for this purpose. Thus enabling the owner of the vehicle to control and monitor the vehicle activities from a faraway place. This system is highly useful in detecting various abnormalities that might take place in the functioning of vehicle. This system provides immediate information to the owner regarding these abnormalities.

\section{SERVICE BASED VECHICLE CONTROL SYSTEM ARCHITECTURE}

The system consists of a microcontroller which is the heart of the system. It contains various sensors which are used for different purposes in the vehicle. It also contains an LCD inside the vehicle to notify the driver about the instructions given to him by the owner.

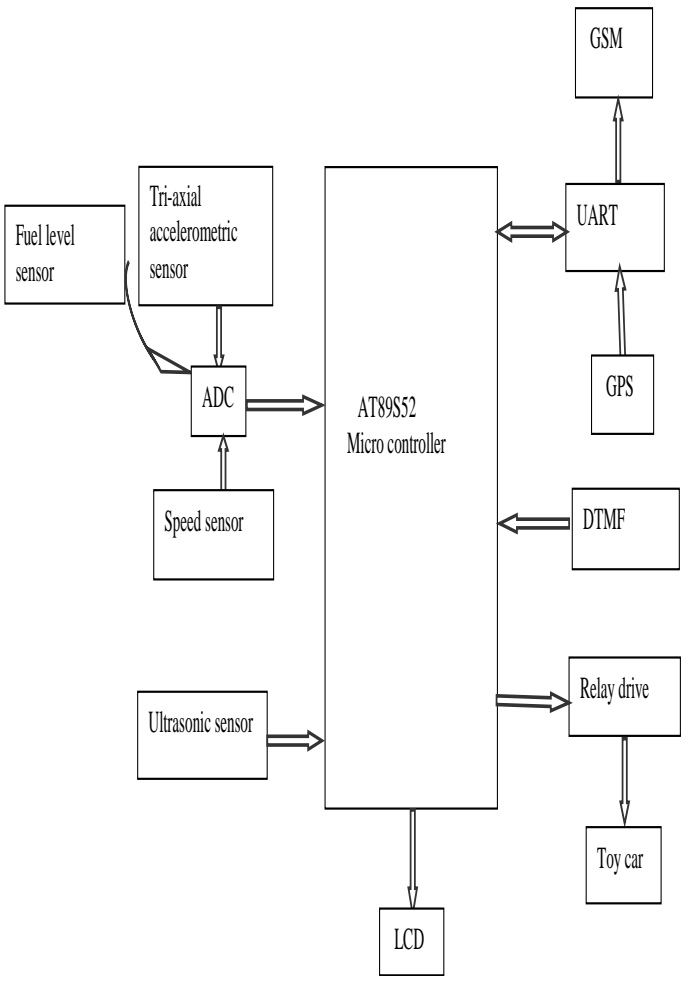

Fig. 1.Vehicle Control Using DTMF

\section{DTMF (DUAL TONE MULTI FREQUENCY)}

The DTMF technique outputs distinct representation of 16 common alphanumeric characters $(0-9, \mathrm{~A}-\mathrm{D}, *, \#)$ on the telephone. The lowest frequency used is $697 \mathrm{~Hz}$ and the highest frequency used is $1633 \mathrm{~Hz}$. The DTMF keypad is arranged such that each row will have its own unique tone frequency and also each column will have its own unique tone frequency. 


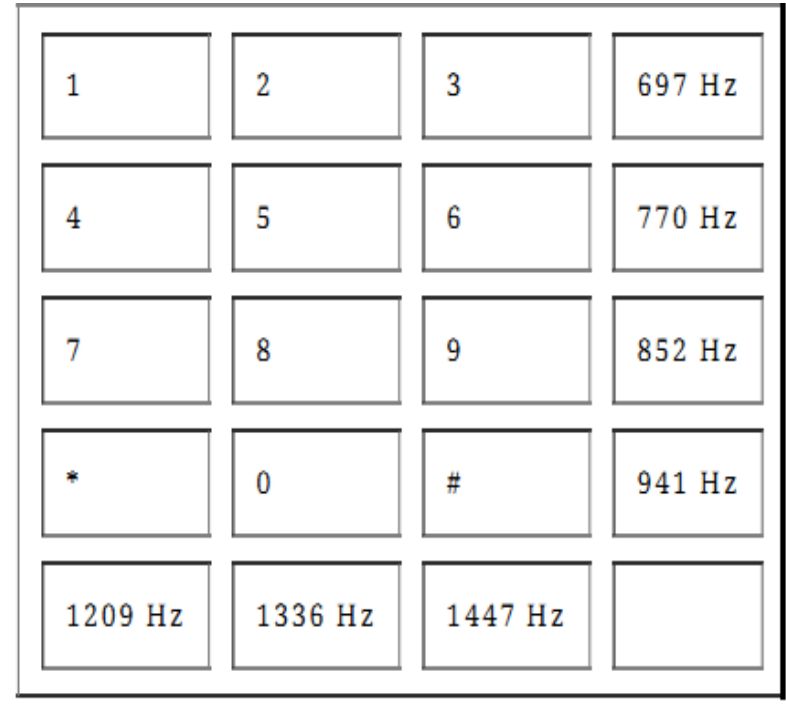

Fig.2 DTMF keypad

It is a representation of the typical DTMF keypad and the associated row/column frequencies. By pressing a key, for example 5, will generate a dual tone consisting of $770 \mathrm{~Hz}$ for the low group and $1336 \mathrm{~Hz}$ for the high group.

\section{HARDWARE COMPONENTS}

\subsection{AT89s52 Microcontroller}

The AT89S52 is a low-power, high-performance CMOS 8-bit microcontroller with $8 \mathrm{~K}$ bytes of in-system programmable Flash memory. The device is manufactured using Atmel's high-density non-volatile memory technology and is compatible with the Indus-try-standard 80C51 instruction set and pin out. The on-chip Flash allows the program memory to be reprogrammed in-system or by a conventional nonvolatile memory pro-grammars. By combining a versatile 8bit CPU with in-system programmable Flash on a monolithic chip, the Atmel AT89S52 is a powerful microcontroller which provides a highly-flexible and cost-effective solution to many embedded control applications.

\subsection{ADC 0808/0809}

The ADC0809 data acquisition component is a monolithic CMOS device with an 8-bit analogue-to-digital converter, 8channel multiplexer and microprocessor compatible control logic. The 8-bit A/D converter uses successive approximation as the conversion technique. The converter features a high impedance chopper stabilized comparator, a $256 \mathrm{R}$ voltage divider with analogue switch tree and a successive approximation register. The 8-channel multiplexer can directly access any of 8-single-ended analogue signals. The device eliminates the need for external zero and full-scale adjustments.

\subsection{LCD}

A number of commands have to be provided to the LCD before giving the required data. LCD doesn't know about the content (data or commands) supplied to its data bus. It is the user who has to specify whether the content at its data pins are data or commands. For this, if a command is given then a particular combination of $0 \mathrm{~s}$ and $1 \mathrm{~s}$ has to be applied to the Control lines so as to specify it is a Command, on the other hand if a data is given at the data lines then an another combination of $0 \mathrm{~s}$ and $1 \mathrm{~s}$ has to be applied to the control lines to specify it.

\subsection{DTMF Receiver}

The MT8870 is a full DTMF Receiver that integrates both band split filter and decoder functions into a single18-pin DIP or SOIC package. Manufactured using CMOS process technology, the M-8870 offers low power consumption (35 $\mathrm{mW} \max$ ) and precise data handling. Its filter section uses switched capacitor technology for both the high and low group filters and for dial tone rejection. Its decoder uses digital counting techniques to detect and decode all 16 DTMF tone pairs into a 4-bit code.

\subsection{GPS}

It provides reliable positioning, navigation, and timing services to worldwide users on a continuous basis in all weather, day and night, anywhere on or near the Earth .GPS is made up of three parts: between 24 and 32 satellites orbiting

the Earth, four control and monitoring stations on Earth, and the GPS receivers owned by users. GPS satellites broadcast signals from space that are used by GPS receivers to provide three-dimensional location (latitude, longitude, and altitude) plus the time.

\subsection{Ultrasonic Sensor}

It can detect objects without physical contact. An ultrasonic sensor often emits an electromagnetic field or beam and look for changes in the field. The object being sensed is often referred to as the ultrasonic sensor's target. The maximum distance that this sensor can detect is defined "nominal range".

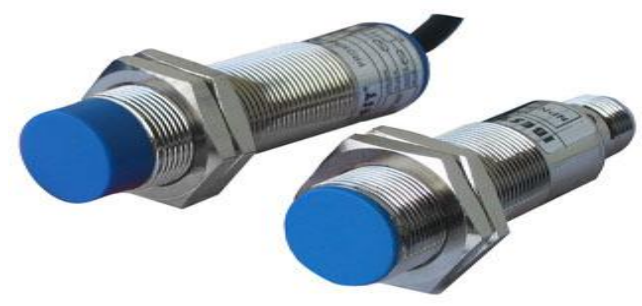

Fig.3 Ultrasonic Sensor

\subsection{Level Sensor}

They detect the level of substances that flow, including liquids, slurries, granular materials, and powders.All such substances flow to become essentially level in their containers (or other physical boundaries) because of gravity. The substance to be measured can be inside a container or can be in its natural form (e.g. a river or a lake).

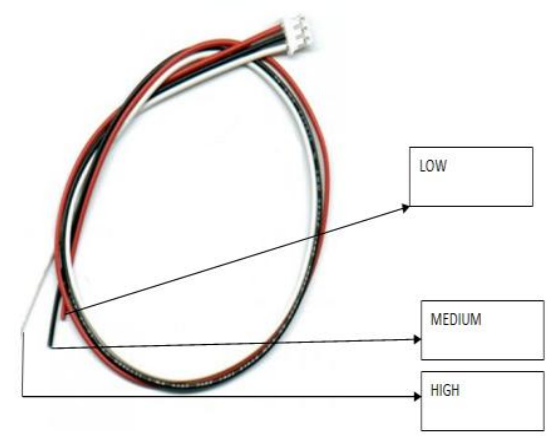

Fig.4 Level Sensor 


\subsection{Relay}

A relay is an electrically operated switch. Current flowing through the coil of the relay creates a magnetic field which attracts a lever and changes the switch contacts. The coil current can be on or off so relays have two switch positions and they are double throw (changeover) switches.

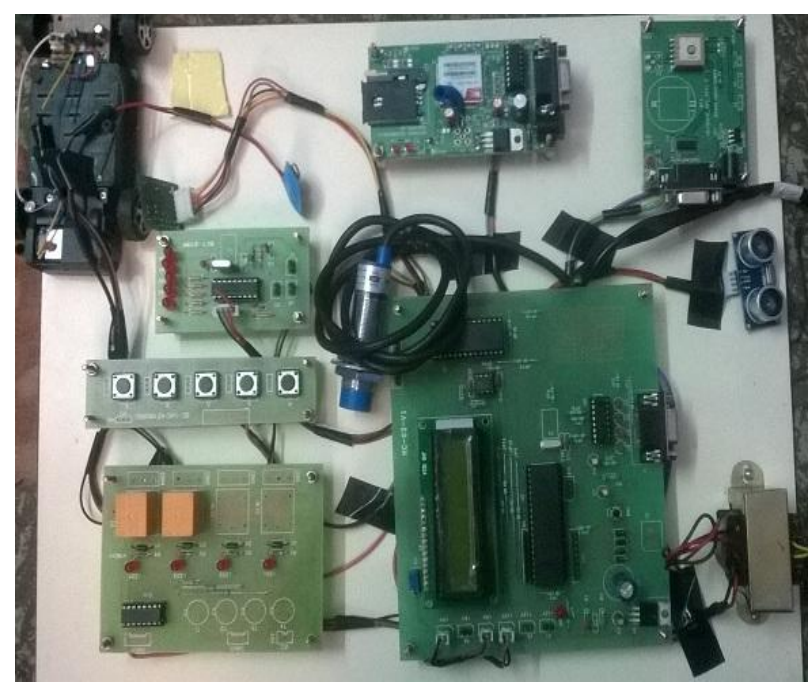

Fig.5 Implemented Hardware

\section{SOFTWARE TECHNIQUES}

\subsection{Embedded $C$}

It is a versatile programming language. In this system, embedded $\mathrm{c}$ is used because It is small and reasonably simpler to learn, understand, program and debug. Unlike assembly, C has advantage of processor-independence and is not specific to any particular microprocessor/ microcontroller or any system. This makes it convenient for a user to develop programs that can run on most of the systems.

\subsection{Keil compiler}

Keil compiler is software used where the machine language code is written and compiled. After compilation, the machine source code is converted into hex code which is to be dumped into the microcontroller for further processing. Keil compiler also supports $\mathrm{C}$ language code.

\section{APPLICATIONS}

\section{- Accident identification}

This system provides immediate information to the owner whenever an accident takes place.

\section{- $\quad$ Speed control}

This system helps to control the speed of the vehicle whenever it exceeds its prescribed limit.

\section{- $\quad$ Theft identification \& control}

This system helps the owner to turn off the vehicle whenever it is stolen.

\section{CONCLUSION}

In this paper the vehicle is controlled by mobile phone using DTMF technology which is a very inexpensive method and the limitation of wired networks is completely overcome by using latest technology of mobile phones. However, there are still lots of scopes to improve the stability and ability of this system. The mobile phone that makes a call to mobile phone stacked in the car act as a remote. The activities of the vehicle can be monitored and controlled from a remote location. This system helps to retrieve information about the vehicle from a remote place.

\section{REFERENCES}

[1] Lian, S.H., "Fuzzy Logic Control of an Obstacle Avoidance Robot",IEEE International Conference of Fuzzy Systems, New Orleans, LA, September 8-1 1, 1996,vol.1,pp.26-30.

[2] Yen-Sheng chen, "Intelligent Obstacle Avoidance Control Strategy for Wheeled Mobile Robot", ICROSSICE,International Joint Conference 2009 August 18-21, 2009, Fukuoka International Congress Center, Japan.

[3] G. Arangurenss, L. Nozal, A. Blazquez, and J. Arias, "Remote control of sensors and actuators by GSM", IEEE 2002 28th Annual Conference of the Industrial Electronics Society IECON 02, vol. , 5-8 Nov. 2002,pp. $2306-2310$.

[4] R. Sharma, K. Kumar, and S. Viq, "DTMF Based Remote Control System," IEEE International Conference ICIT 2006, pp. 2380-2383, December 2006.

[5] Balasubramanian, K., "Object recognition and obstacle avoidance robot", IEEE 17-19 June 2009 Chinese Control and Decision Conference (CCDC 2009).

[6] C.K.Gomathy and Dr.S.Rajalakshmi,"Software Pattern Quality Comportment In Service Oriented Architectures", European Scientific Journal (ESJ) volume-10,No-9,Issue-March 2014,P.No-412-423,ISSN$1857-7881$.

[7] S. Chemishkian, "Building smart services for smart home", Proceedings of IEEE 4thInternational Workshop on Networked Appliances, 2011 pp: 215 -224.

[8] C.K.Gomathy and Dr.S.Rajalakshmi.(2014),"A Software Ability link for Service Oriented Architecture", Global Journal of Management and Business Research (GJMBR), Volume(A) XIV, Issue-II, Version 1.0,May 2014, P.No:11-14, ISSN:2249-4588.

[9] R.C. Luo, T.M. Chen, and C.C. Yih, "Intelligent autonomous mobile robot control through the Internet,"IEEE International Symposium ISIE 2000, vol. 1, pp. 6-11, December 2000. 